\title{
Prevalence of Dyslipidemia and Management in the Thai Population, National Health Examination Survey IV, 2009
}

\author{
Wichai Aekplakorn, ${ }^{1,2}$ Surasak Taneepanichskul, ${ }^{3}$ \\ Pattapong Kessomboon, ${ }^{4}$ Virasakdi Chongsuvivatwong, ${ }^{5}$ Panwadee Putwatana, ${ }^{6}$ \\ Piyamitr Sritara, ${ }^{7}$ Somkiat Sangwatanaroj, ${ }^{8}$ and Suwat Chariyalertsak ${ }^{9}$
}

\author{
${ }^{1}$ Department of Community Medicine, Faculty of Medicine, Ramathibodi Hospital, Mahidol University, \\ Rama VI Road, Rajdevi, Bangkok 10400, Thailand \\ ${ }^{2}$ National Health Examination Survey Office, Nonthaburi, Nonthaburi 11000, Thailand \\ ${ }^{3}$ College of Public Health Sciences, Chulalongkorn University, Bangkok 10330, Thailand \\ ${ }^{4}$ Faculty of Medicine, Khon Kaen University, Khon Kaen 40002, Thailand \\ ${ }^{5}$ Epidemiology Unit, Faculty of Medicine, Prince of Songkla University, Songkhla 90110, Thailand \\ ${ }^{6}$ Ramathibodi School of Nursing, Faculty of Medicine, Ramathibodi Hospital, Bangkok 10400, Thailand \\ ${ }^{7}$ Department of Medicine, Faculty of Medicine, Ramathibodi Hospital, Bangkok 10400, Thailand \\ ${ }^{8}$ Department of Medicine, Faculty of Medicine, Chulalongkorn University, Bangkok 10330, Thailand \\ ${ }^{9}$ Faculty of Medicine, Chiang Mai University, Chiang Mai 50002, Thailand
}

Correspondence should be addressed to Wichai Aekplakorn; wichai.aek@mahidol.ac.th

Received 10 December 2013; Accepted 25 February 2014; Published 30 March 2014

Academic Editor: David J. A. Jenkins

\begin{abstract}
Copyright (C) 2014 Wichai Aekplakorn et al. This is an open access article distributed under the Creative Commons Attribution License, which permits unrestricted use, distribution, and reproduction in any medium, provided the original work is properly cited.

This study determined the prevalence and management of dyslipidemia in Thai adults using data from the Thai National Health Examination Survey IV in 2009. Dyslipidemia was defined based on the Third Adult Treatment Panel guidelines. A total of 19,021 adults aged $20 \mathrm{yr}$ and over were included. Mean (SE) levels of total cholesterol, HDL-C, LDL-C, and triglycerides were 206.4 (1.03), 46.9 (0.34), 128.7 (1.09), and 131.4 (2.20) $\mathrm{mg} / \mathrm{dL}$, respectively. Prevalence of high LDL-C, low HDL-C, and high triglycerides were $29.6 \%, 47.1 \%$, and 38.6\%, respectively. Compared with individuals in the north and northeast, residents in Bangkok and Central region had significant higher levels of LDL-C but lower level of HDL-C. Triglyceride level was the highest in the northeast residents. Overall, $66.5 \%$ of Thais had some forms of dyslipidemia. Awareness and treatment of high LDL-C among those with high LDL-C were $17.8 \%$ and $11.7 \%$, respectively. Among individuals aware of high LDL-C, those at highest CHD risk compared with those at low risk had higher percentage of treatment (73.1\% versus 51.7\%, resp.) but lower percentage of control at goal (32.9\% versus $76.4 \%$, resp.). Various forms of dyslipidemia are common in Thai adults, with a low level of awareness and treatment of high LDL-C.
\end{abstract}

\section{Introduction}

Association of dyslipidemia with the development of cardiovascular disease (CVD) is well established and guidelines for management of the condition have already been issued [1-5]. Serum total cholesterol other than its subtypes is usually used as a measure for monitoring at the population level, especially in developing countries. In the past few decades, data from several countries reported a high prevalence of dyslipidemia and unsatisfactory results of dyslipidemia management [612]. Recently, a multicountry analysis of national health examination survey data from eight countries on various continents reported disappointing findings of low detection and inadequate management of high serum cholesterol, particularly among middle-income countries [12]. Among these countries, Thailand in 2004 had the highest (78\%) percentage of unawareness of hypercholesterolemia, with markedly low percentages of treatment and control. In clinical practice, 
low-density lipoprotein cholesterol (LDL-C) is usually the primary target for lipid management [1]. Recent studies suggest that low HDL-C and high triglycerides also confer residual risk for CVD $[13,14]$. However, there is no Thai data on the prevalence of other lipid parameters-for example, high-density lipoprotein cholesterol (HDL-C), non-HDL-C, LDL-C, and triglycerides-in the general population, with and without CVD risk factors. Previous studies on the percentage of attaining LDL-C goals recommended by the Third Adult Treatment Panel (ATP III) cholesterol guidelines in 2001 [1] were based on hospital data [15-17]. The fourth National Health Examination Survey conducted in 2009 (NHES, 2009) was the first national survey in Thailand by which major lipid parameters including total cholesterol, HDL-C, and triglyceride were measured. The present study aimed to document the distribution of lipid parameters and prevalence of dyslipidemia among Thai adults aged $\geq 20$ years old according to age, sex, area of residence, and geographic region. This report could provide useful information for prevention and control of dyslipidemia as well as baseline data for monitoring and evaluation at the national level.

\section{Methods}

The survey was approved by the Ethical Review Committee for Research in Human Subjects, Ministry of Public Health. The design of NHES 2009 was described elsewhere [18]. Briefly, it was based on a multistage probability sampling technique where sampling units in each of the four stages were (1) five provinces in each of the four main regions (north, northeast, central, and south) and Bangkok, (2) two to three districts in each selected province, (3) 13-14 enumeration units (EU)/villages in each district, and (4) individuals among six age groups $(15-29,30-44,45-59,60-69,70-79$, and $\geq 80$ years) of each gender from each EU/village. The final sample size was 20,426 and the response rate was $93.1 \%$. The present analysis omitted adolescents (age $<20$ years), keeping 9,021 men and 10,000 women in the study. Urban area was defined by the Thai National Statistical Office as a municipal area in each province, including the entire Bangkok metropolis and officially designated sanitary district which is a locality achieving a minimum population size and density and income, and the remainders of the country were rural areas.

2.1. Data Collection and Measurement. Key variables included demographic data, behavioral risk factors, medical history of previously diagnosed diabetes, hypertension, and high blood cholesterol; and whether on medication. Blood pressure was measured using a standardized automatic blood pressure monitor (model A100; Microlife, Taipei, Taiwan). Each participant was seated for at least $5 \mathrm{~min}$ before the first reading of three serial measurements of blood pressure taken $1 \mathrm{~min}$ apart while in a sitting position. Venous blood samples were obtained from participants in the morning after fasting $12 \mathrm{~h}$ overnight. Plasma glucose was measured using a hexokinase enzymatic method. Serum samples were frozen and transferred to a central laboratory in Ramathibodi Hospital, Mahidol University, Bangkok. Serum total cholesterol and triglycerides were analyzed using enzymatic colorimetric methods (CHOD-PAP and GPOPAP, resp.). High-density lipoprotein cholesterol (HDL-C) was measured using homogeneous enzymatic colorimetric method. Low-density lipoprotein cholesterol (LDL-C) was calculated based on the Friedewald formula [19] for subjects with triglycerides $<4.5 \mathrm{mmol} / \mathrm{L}(400 \mathrm{mg} / \mathrm{dL})$ and was directly measured by enzymatic method for those having triglycerides $\geq 4.5 \mathrm{mmol} / \mathrm{L}(400 \mathrm{mg} / \mathrm{dL})$. All lipid measurements were carried out using a Hitachi 917 biochemistry analyzer (Roche Diagnostics, Basel, Switzerland). The laboratory was standardized according to the criteria of the Lipid Standardization Program of the Centers for Disease Control and Prevention and the National Heart, Lung, and Blood Institute [20].

2.2. Dyslipidemia. Recommended lipid levels were classified based on the guidelines of the Adult Treatment Panel III (ATP III) of the National Cholesterol Education Program [1, 2]. For estimation of coronary heart disease (CHD) risk, we used the World Health Organization (WHO) risk prediction charts for Southeast Asian countries (SEAR B) including Thailand to assign the 10-year CHD risk [21]. Variables used to categorize CHD risk included sex, age, diabetes status, systolic blood pressure, smoking status, and total cholesterol level. Low HDL-C was defined as HDL-C $<1.03 \mathrm{mmol} / \mathrm{L}(40 \mathrm{mg} / \mathrm{dL})$ in men and $<1.30 \mathrm{mmol} / \mathrm{L}(50 \mathrm{mg} / \mathrm{dL})$ in women. The cutoff points for high LDL-C were defined as follows: high risk, LDL-C $\geq 100 \mathrm{mg} / \mathrm{dL}$ if having prior CHD or CHD equivalent or having 10 -year $\mathrm{CHD}$ risk $>20 \%$; moderate risk, LDL-C $\geq 130 \mathrm{mg} / \mathrm{dL}$ if having $\geq 2$ risk factors (RF) and/or 10-year CHD risk $10 \%$ to $20 \%$; and lower risk, LDL-C $\geq 160 \mathrm{mg} / \mathrm{dL}$ if having $0-1 \mathrm{RF}$. Other major independent risk factors, according to ATP III, include smoking, hypertension (systolic blood pressure $\geq 140 \mathrm{mmHg}$ or diastolic blood pressure $\geq 90 \mathrm{mmHg}$ or on antihypertensive medication), low HDL$\mathrm{C}(<40 \mathrm{mg} / \mathrm{dL})$, family history of premature CHD, or CHD in a first-degree relative (men $<55$ yrs and women $<65 \mathrm{yrs}$ ), and age (men $\geq 45 \mathrm{yrs}$ and women $\geq 55 \mathrm{yrs}$ ). If a person has high HDL-C ( $\geq 60 \mathrm{mg} / \mathrm{dL})$, then one RF would be subtracted from the count. High non-HDL-C was defined based on the CHD risk similar to high LDL-C, with cutoff points for non-HDL-C of 190, 160 and $130 \mathrm{mg} / \mathrm{dL}$ corresponding to LDL-C levels of 160 , and 130 and $100 \mathrm{mg} / \mathrm{dL}$, respectively. Diabetes was defined as having a previous diagnosis of diabetes by a physician and currently taking hypoglycemic drugs during the prior two weeks, or those having fasting plasma glucose $\geq 7.0 \mathrm{mmol} / \mathrm{L}(126 \mathrm{mg} / \mathrm{dL})$. Hypertension was defined as systolic blood pressure (SBP) $\geq 140 \mathrm{mmHg}$ or diastolic blood pressure (DBP) $\geq 90 \mathrm{mmHg}$, or use of blood pressure-lowering medication. In order to explore the picture of isolated and combined abnormal lipid parameters, a mixed dyslipidemia condition was categorized into eight groups as follows: (1) isolated high LDL-C; (2) isolated low HDL-C; (3) combined high LDL-C and low HDL-C; (4) isolated high triglycerides ( $>2.26 \mathrm{mmol} / \mathrm{L}, 200 \mathrm{mg} / \mathrm{dL}$ ); (5) combined high 
LDL-C and high triglycerides; (6) combined low HDL-C and high triglycerides; (7) combined high LDL-C, low HDL-C, and high triglycerides; and (8) no dyslipidemia.

For calculation of awareness, treatment and control of high LDL-C, subjects who answered "Yes" to the question "Have you ever been told by a health professional or physician that you had high blood cholesterol?" were considered to be aware of the condition. Undergoing treatment for high blood cholesterol was defined as an affirmative response to the question "Have you taken medication for lowering blood cholesterol in the past two weeks?" We calculated the percentage of individuals who were aware of the condition. The percentage of treatment was calculated for all participants with high LDL-C and for those aware of the condition. The percentage of controlled LDL-C was calculated for all participants with high LDL-C and for those receiving treatment.

2.3. Statistical Methods. Complex survey analysis was employed to take into account the probability sampling design. All lipid parameters were presented as age-adjusted arithmetic mean, except triglycerides for which geometric mean was calculated due to the skewed distribution. The age-adjusted prevalences of high LDL-C, low HDL-C, and high triglycerides were calculated overall and for subgroups according to age group, sex, area of residence, geographic region, and educational level, as well as for those with comorbidity of diabetes or hypertension and according to $\mathrm{CHD}$ risk categories. We also calculated the age-adjusted prevalence of mixed dyslipidemia for men and women. All comparisons were age- and sex-standardized to the national population in 2008. Adjusted Wald tests were used to examine the differences, with $P<0.05$ considered statistically significant. We used linear regression to evaluate linear trend of each lipid parameter level by age groups and CHD risk stratification, and reported the $P$ value for trend. For evaluation of trends in prevalence of each lipid abnormality by age group and CHD risk, logistic regression model was used. All of the analyses were performed using Stata statistical software version 10 (StataCorp, College Station TX, USA).

\section{Results}

Table 1 shows the age-adjusted means (SE) of total cholesterol, HDL-C, non-HDL-C and LDL-C, total cholesterol to HDL-C ratio (TC/HDL-C) and geometric mean of triglycerides among Thai adults aged $\geq 20$ yrs. Overall, the age-adjusted means of total cholesterol, HDL-C, non-HDL-C, and LDL$\mathrm{C}$ (but not triglycerides and TC/HDL-C) were higher in women than in men (all $P<0.001$ ) as well as in urban areas compared with rural areas (all $P<0.01$ ). All lipid levels, except HDL-C, were higher in men of middle age (35$59 \mathrm{yrs})$ and in women of older age ( $\geq 60 \mathrm{yrs}$ ). There were slight differences in lipid parameters according to region. Individuals who resided in Bangkok, south and central regions, had higher levels of LDL-C, non-HDL-C, and HDL-C but had lower levels of triglycerides than those living in the northern and northeastern regions. Individuals with diabetes or hypertension had a markedly higher level of triglycerides than those without these conditions (all $P<$ 0.01 ). Those with higher CHD risk were more likely to have unfavorable levels of HDL-C and triglycerides compared with those categorized as low CHD risk.

Figure 1 displays the age-adjusted prevalence of dyslipidemia by area of residence and sex. Overall, the age-adjusted prevalence of high LDL-C and of high non-HDL-C were similar for men and women. Women had higher prevalence of low HDL-C but lower prevalence of high triglycerides compared with men $(P<0.01)$. Urban residents had higher prevalence of both high LDL-C and high non-HDL-C, whereas rural residents had higher prevalence of low HDLC. For high triglycerides, the prevalence in urban/rural areas differed by sex; there was no significant difference between urban and rural areas among men, but the prevalence was higher for women in rural areas compared with their counterparts in urban areas.

Figure 2 shows the age-adjusted prevalence of dyslipidemia for each parameter and the combined lipid parameters for men and women. Overall, $22.2 \%$ had isolated low HDLC (14.2\% in men versus $31.2 \%$ in women, $P<0.05), 12.8 \%$ had isolated high LDL-C (15.2\% in men versus $10.4 \%$ in women), $4.2 \%$ had high triglycerides $(7 \%$ in men versus $1.5 \%$ in women), and $4.8 \%$ had a combination of three lipid abnormalities ( $4.7 \%$ in men versus $4.9 \%$ in women). About $6 \%$ of men and $13.5 \%$ of women had combined low HDL-C and high LDL-C, while $10.6 \%$ of men and $9 \%$ of women had combined low HDL-C and high triglycerides. The prevalence of high LDL-C combined with high triglycerides was 3.5\% in men and $1.2 \%$ in women. Thus, $33.5 \%$ of Thai adults had no dyslipidemia ( $38.7 \%$ of men and $28.3 \%$ of women).

Table 2 shows that people in the northeast tended to have higher prevalence of high triglycerides and low HDL-C, whereas people in the south and Bangkok tended to have higher prevalence of high LDL-C but lower prevalence of low HDL-C. Individuals with diabetes or hypertension had higher percentages of dyslipidemia including high LDL-C and high triglycerides. Men with diabetes and women with hypertension were more likely to have higher prevalence of low HDL-C compared with those without the conditions.

Table 3 shows the age-adjusted prevalence of awareness, treatment, and control of high LDL-C. Overall, $17.8 \%$ of those with high LDL-C were aware that they had high LDL-C, and the percentages of treated and controlled among all individuals with high LDL-C were markedly low (11.7 and $6.3 \%$, resp.). However, among those aware of their condition, $60.6 \%$ overall were treated; of those treated, $57.6 \%$ had LDL-C at recommended levels. Low percentages of awareness and treatment were observed for all characteristics; the percentages were slightly higher among individuals in urban areas compared with those in rural areas and also were higher in Bangkok compared with other regions. Note that the percentages of treatment among those aware of their diagnosis were higher for those with diabetes, hypertension, or high risk of $\mathrm{CHD}$ than those without these conditions; 


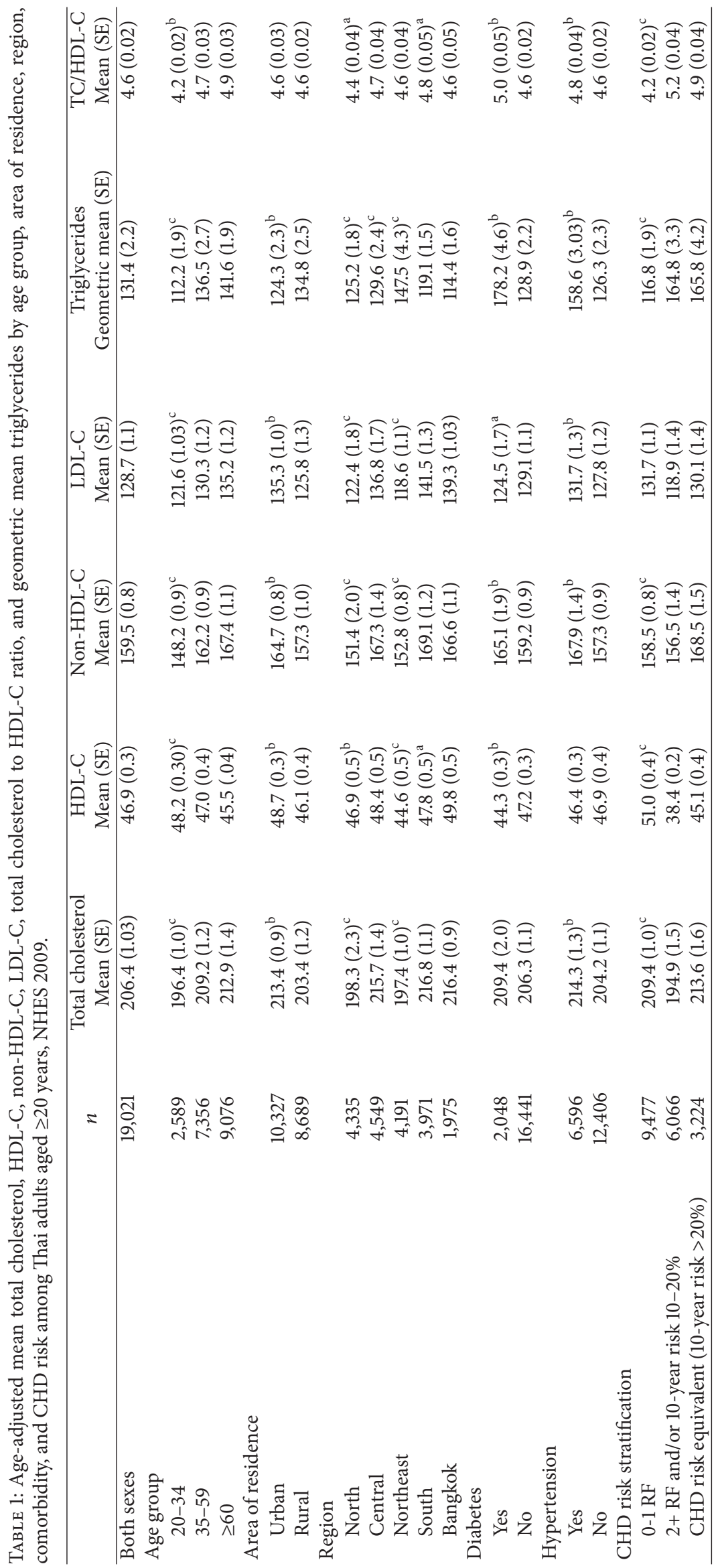




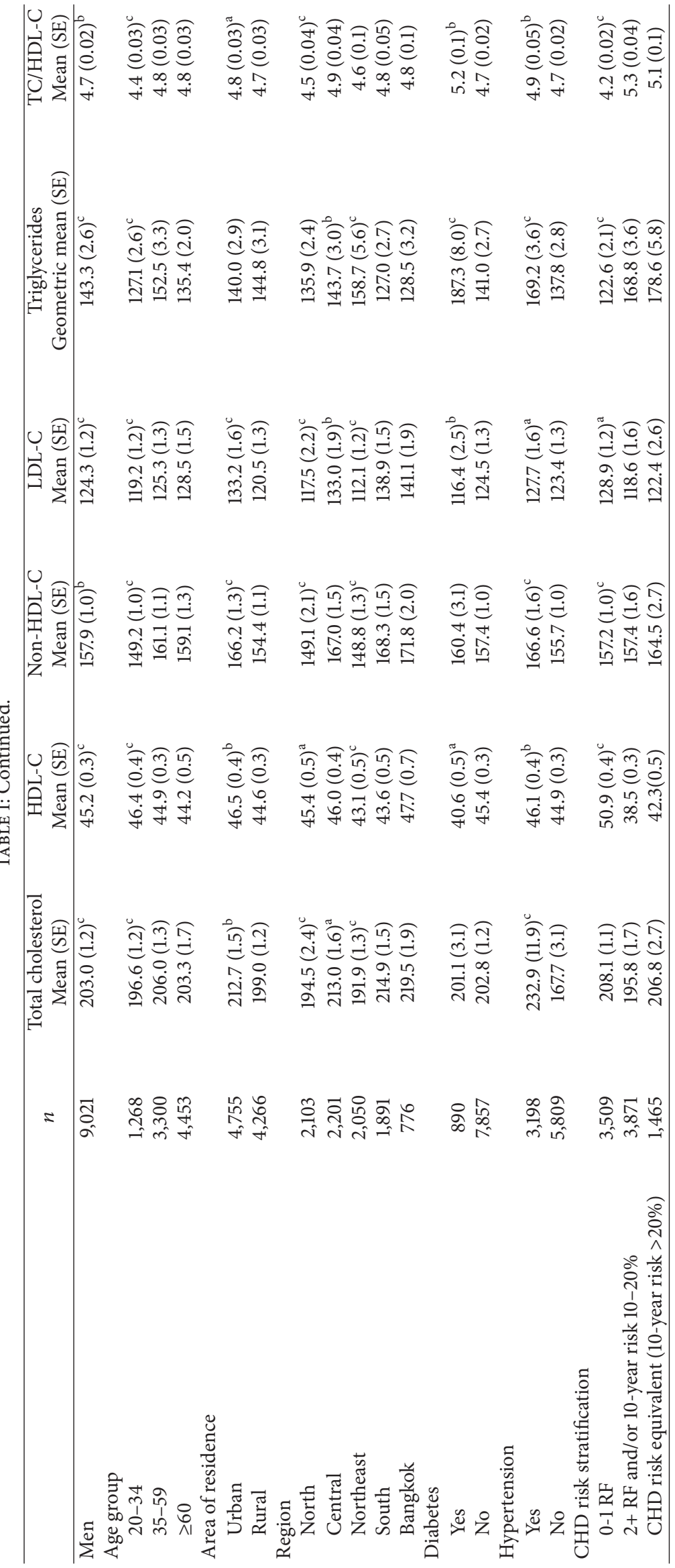




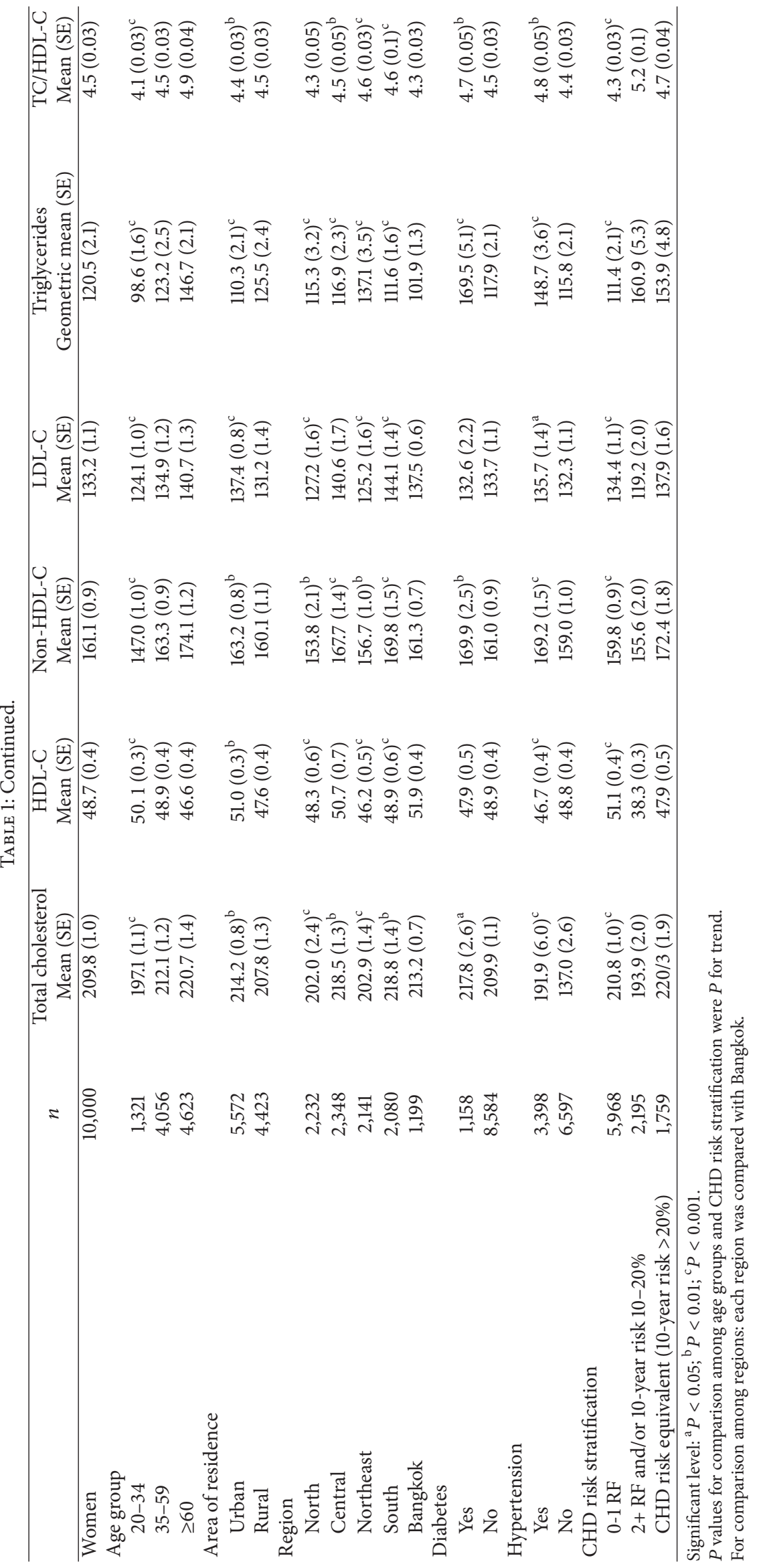


TABLE 2: Age-adjusted prevalence of high total cholesterol, high LDL-C, low HDL-C, high non-HDL-C, and high triglycerides by age group, area of residence, region, comorbidity, and CHD risk among Thai men and women aged $\geq 20$ years, NHES 2009.

\begin{tabular}{|c|c|c|c|c|c|}
\hline & $n$ & $\%$ High LDL-C ${ }^{*}$ & $\begin{array}{c}\text { \% Low HDL-C } \\
(<40 / 50)\end{array}$ & $\%$ High non-HDL-C & $\begin{array}{l}\text { \% High triglycerides } \\
(\geq 150)\end{array}$ \\
\hline Both sexes & 19,021 & $29.6(0.9)$ & $47.1(1.0)$ & $32.6(0.8)$ & $38.6(1.4)$ \\
\hline Men & 9,021 & $29.5(1.0)$ & $35.6(1.1)^{\mathrm{c}}$ & $34.0(0.9)^{\mathrm{b}}$ & $44.3(1.7)^{\mathrm{c}}$ \\
\hline Women & 10,000 & $29.7(0.9)$ & $58.6(1.2)$ & $31.2(0.8)$ & $32.9(1.2)$ \\
\hline \multicolumn{6}{|l|}{ Men } \\
\hline \multicolumn{6}{|l|}{ Region } \\
\hline North & 2,103 & $22.6(2.0)^{\mathrm{c}}$ & $35.1(1.8)^{\mathrm{b}}$ & $26.3(1.9)^{\mathrm{c}}$ & $41.7(1.3)^{\mathrm{a}}$ \\
\hline Central & 2,201 & $38.2(1.5)$ & $32.5(1.0)^{\mathrm{b}}$ & $42.1(1.5)$ & $42.4(1.9)^{\mathrm{a}}$ \\
\hline Northeast & 2,050 & $19.3(0.9)^{\mathrm{c}}$ & $42.9(1.9)^{\mathrm{c}}$ & $26.2(1.3)^{\mathrm{c}}$ & $52.5(3.6)^{\mathrm{c}}$ \\
\hline South & 1,891 & $42.0(1.5)$ & $29.4(0.9)$ & $44.2(1.4)$ & $33.4(1.8)$ \\
\hline Bangkok & 776 & $42.2(2.4)$ & $26.5(1.4)$ & $44.0(2.4)$ & $36.9(0.9)$ \\
\hline \multicolumn{6}{|l|}{ Diabetes } \\
\hline Yes & 890 & $66.6(2.8)^{\mathrm{c}}$ & $54.6(3.1)^{\mathrm{c}}$ & $79.7(2.4)^{\mathrm{c}}$ & $55.3(1.4)^{\mathrm{c}}$ \\
\hline No & 7,857 & $28.0(1.1)$ & $34.2(1.1)$ & $32.1(0.9)$ & $41.4(2.0)$ \\
\hline \multicolumn{6}{|l|}{ Hypertension } \\
\hline Yes & 3,198 & $39.1(1.7)^{\mathrm{c}}$ & $35.3(1.3)$ & $47.9(1.7)^{\mathrm{c}}$ & $55.3(1.4)^{\mathrm{c}}$ \\
\hline No & 5,809 & $26.4(0.9)$ & $35.9(1.2)$ & $29.7(0.8)$ & $41.4(2.0)$ \\
\hline \multicolumn{6}{|l|}{$\mathrm{CHD}$ risk stratification } \\
\hline $0-1 \mathrm{RF}$ & 3,509 & $19.4(1.0)^{\mathrm{c}}$ & $9.4(0.5)^{\mathrm{c}}$ & $19.3(0.8)^{\mathrm{c}}$ & $32.8(1.5)^{\mathrm{c}}$ \\
\hline $2+\mathrm{RF}$ and/or 10-year risk $10-20 \%$ & 3,871 & $35.1(1.8)$ & $72.1(1.3)$ & $44.5(1.7)$ & $54.3(2.2)$ \\
\hline CHD risk equivalent (10-year risk > 20\%) & 1,465 & $70.8(2.7)$ & $47.9(2.8)$ & $80.5(2.0)$ & $59.6(2.7)$ \\
\hline \multicolumn{6}{|c|}{ Women } \\
\hline \multicolumn{6}{|l|}{ Region } \\
\hline North & 2,232 & $23.3(1.9)^{\mathrm{c}}$ & $60.4(2.2)^{\mathrm{c}}$ & $24.7(1.9)^{\mathrm{b}}$ & $30.5(1.8)^{\mathrm{c}}$ \\
\hline Central & 2,348 & $34.8(2.0)$ & $50.2(2.6)$ & $35.8(1.6)^{\mathrm{a}}$ & $29.7(1.5)^{c}$ \\
\hline Northeast & 2,141 & $25.5(1.0)^{\mathrm{c}}$ & $66.8(1.6)^{\mathrm{c}}$ & $29.1(1.1)$ & $41.4(1.9)^{\mathrm{c}}$ \\
\hline South & 2,080 & $38.2(1.0)^{\mathrm{c}}$ & $58.3(2.6)^{\mathrm{b}}$ & $37.0(1.7)^{\mathrm{a}}$ & $28.1(1.0)^{\mathrm{c}}$ \\
\hline Bangkok & 1,199 & $32.5(1.0)$ & $47.4(1.2)$ & $31.8(0.8)$ & $22.6(0.8)$ \\
\hline \multicolumn{6}{|l|}{ Diabetes } \\
\hline Yes & 1,158 & $73.4(2.5)^{\mathrm{c}}$ & $59.6(2.7)$ & $78.0(2.4)^{\mathrm{c}}$ & $47.6(2.6)^{\mathrm{c}}$ \\
\hline No & 8,584 & $27.0(0.9)$ & $57.8(1.3)$ & $28.1(0.8)$ & $30.2(1.3)$ \\
\hline \multicolumn{6}{|l|}{ Hypertension } \\
\hline Yes & 3,398 & $42.0(1.5)^{\mathrm{c}}$ & $66.0(1.5)^{\mathrm{c}}$ & $45.4(1.6)^{\mathrm{c}}$ & $47.6(2.6)^{\mathrm{c}}$ \\
\hline No & 6,597 & $25.2(0.9)$ & $58.0(1.3)$ & $26.0(0.9)$ & $30.2(1.3)$ \\
\hline \multicolumn{6}{|l|}{$\mathrm{CHD}$ risk stratification } \\
\hline $0-1 \mathrm{RF}$ & 5,968 & $20.8(0.8)^{c}$ & $51.4(1.3)^{\mathrm{c}}$ & $20.6(0.7)^{\mathrm{c}}$ & $26.6(1.2)^{\mathrm{c}}$ \\
\hline $2+\mathrm{RF}$ and/or 10-year risk $10-20 \%$ & 2,195 & $34.7(2.0)$ & $90.2(0.9)$ & $39.8(2.1)$ & $54.9(3.5)$ \\
\hline CHD risk equivalent (10-year risk >20\%) & 1,759 & $76.5(1.9)$ & $58.8(2.5)$ & $(1.6)$ & $55.2(3.1)$ \\
\hline
\end{tabular}

${ }^{*}$ High LDL-C is based on ATP III classification, in which the CHD risk was calculated from the WHO CVD risk chart.

Significant level: ${ }^{\mathrm{a}} P<0.05 ;{ }^{\mathrm{b}} P<0.01 ;{ }^{\mathrm{c}} P<0.001$.

$P$ values for comparison among age groups and among CHD risk stratification were $P$-for trend

For comparison among regions: each region was compared with Bangkok. 

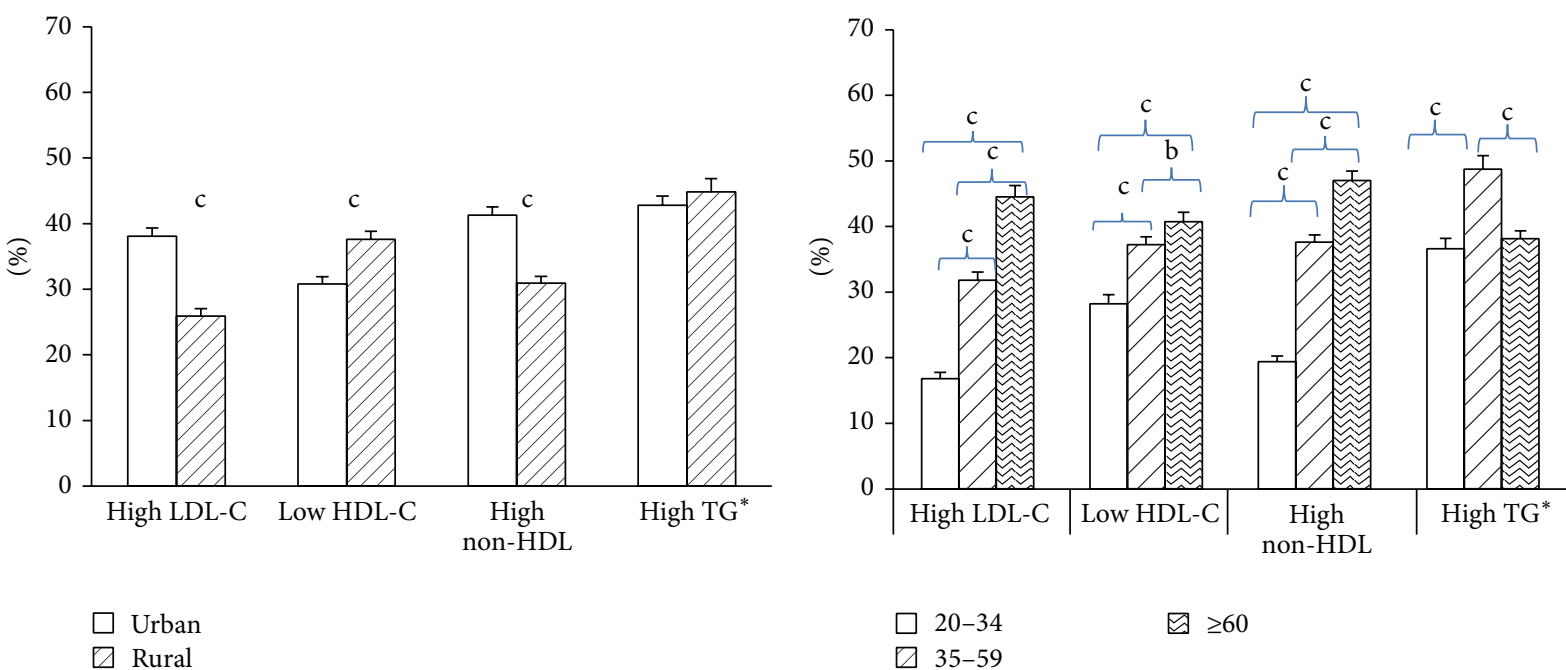

$\begin{array}{ll}\square & 20-34 \\ \square & 35-59\end{array}$

目 $\geq 60$

(a) Men, uban/rural
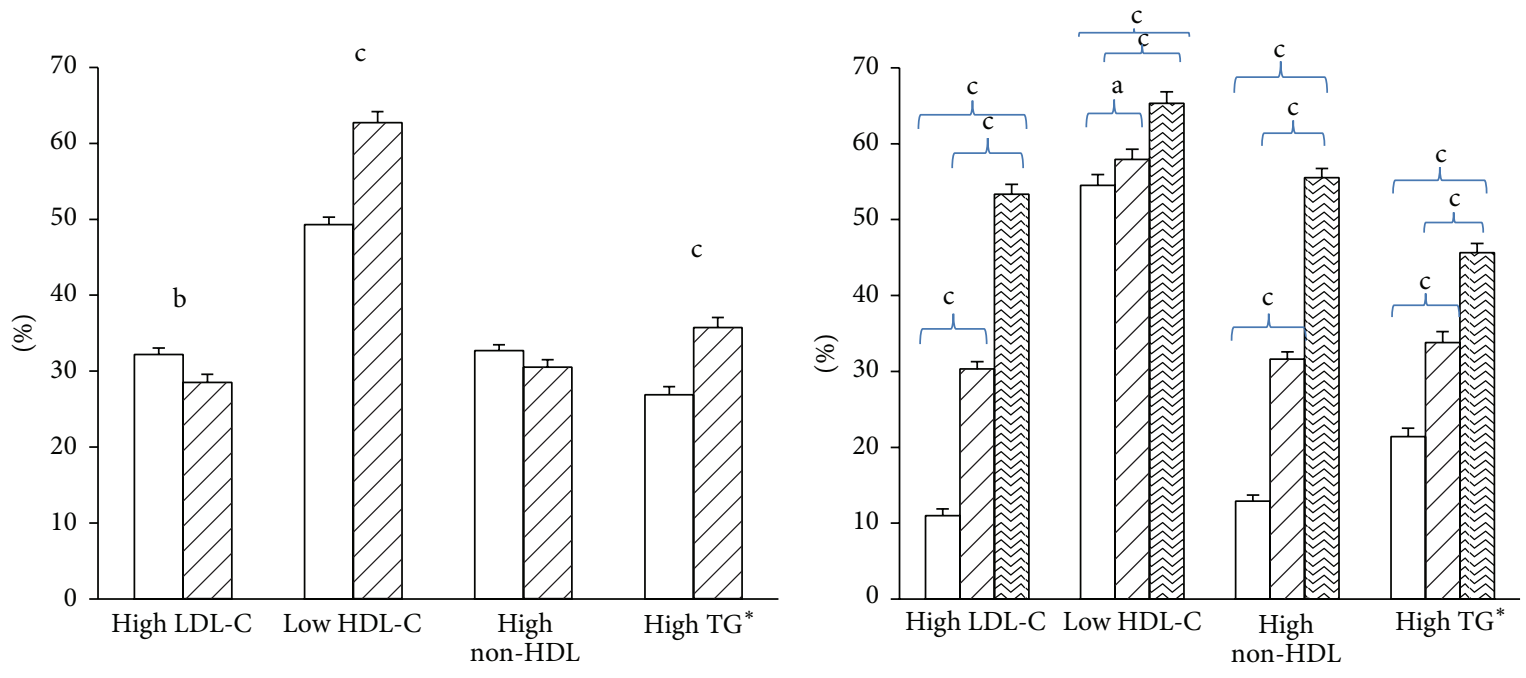

$\square$ Urban

$\square$ 20-34

$\square 35-59$

(b) Men, age group (yr)

(c) Women, uban/rural

(d) Women, age group (yr)

Figure 1: Age-adjusted prevalence of dyslipidemia by area of residence ((a) and (c)) and age-specific prevalence of dyslipidemia ((b) and (d)) among Thai men and women aged $\geq 20$ years, NHES IV 2009. Upper error bars indicate SE values. Significant level: $a, P<0.05 ; b, P<0.01$; c, $P<0.001$.

however, the percentages of controlled among those treated were the opposite.

\section{Discussion}

The present study demonstrated a high prevalence of dyslipidemia in the Thai population. There were significantly different patterns of lipid abnormality by sex, urban/rural areas, and geographic regions. High LDL-C was more prevalent in individuals residing in urban areas than in rural areas, and also was more common in Bangkok, the south and central regions, than in the north and northeast, where people were more likely to have lower HDL-C and high triglyceride levels.
The prevalence of dyslipidemia was also worse among those with comorbidity of diabetes, hypertension, and increased CHD risk. The present study also revealed that 8 in 10 of the individuals with high LDL-C remained unaware and not treated.

Compared with the lipid levels of the U.S. population in 2007-2010, Thai people have higher levels of TC (206 versus $196 \mathrm{mg} / \mathrm{dL}$ ), LDL-C (128.7 versus $116 \mathrm{mg} / \mathrm{dL}$ ), non-HDL-C (158.5 versus $144 \mathrm{mg} / \mathrm{dL}$ ), and triglycerides (geometric mean, 131.45 versus $110 \mathrm{mg} / \mathrm{dL}$ ) but lower HDL-C (46.93 versus $52.5 \mathrm{mg} / \mathrm{dL}$ ) [7, 22]. The current cholesterol levels of the Thai population are comparable to the levels in the U.S. in 19881994 [23]. The level of HDL-C in the Thai population is 


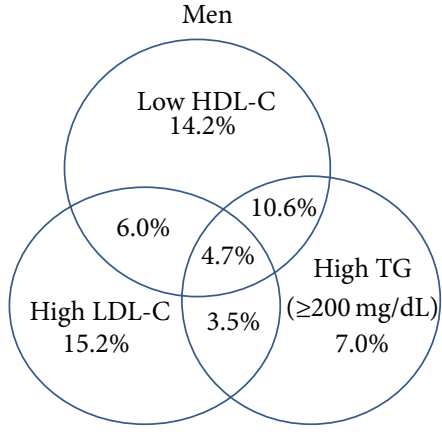

No dyslipidemia $38.7 \%$

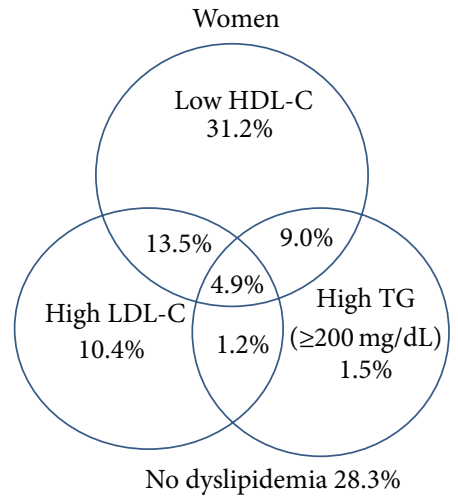

No dyslipidemia $28.3 \%$

FIgURE 2: Age-adjusted prevalence of each lipid abnormality and mixed dyslipidemia in Thai men and women aged $\geq 20$ years, NHES IV 2009.

TABLE 3: Age-adjusted proportions of awareness, treatment, and control of high LDL-C among Thai adults aged $\geq 20$ years with high LDL-C.

\begin{tabular}{|c|c|c|c|c|c|}
\hline & $\%$ Aware & $\begin{array}{l}\text { \% Treated among } \\
\text { high LDL-C }\end{array}$ & $\begin{array}{c}\% \text { Treated among } \\
\text { aware of high LDL-C }\end{array}$ & $\begin{array}{l}\text { \% Control among } \\
\text { high LDL-C }\end{array}$ & $\begin{array}{c}\% \text { LDL-C at } \\
\text { recommended } \\
\text { level among treated }\end{array}$ \\
\hline Total & $17.8(1.1)$ & $11.7(0.8)$ & $60.6(1.5)$ & $6.3(0.5)$ & $57.6(2.7)$ \\
\hline \multicolumn{6}{|l|}{ Sex } \\
\hline Men & $14.3(1.2)^{\mathrm{b}}$ & $9.2(0.9)^{c}$ & $56.1(2.4)^{\mathrm{a}}$ & $4.5(0.5)^{\mathrm{c}}$ & $54.0(3.4)$ \\
\hline Women & $21.2(1.2)$ & $14.2(0.9)$ & $65.1(2.2)$ & $8.2(0.7)$ & $61.2(2.9)$ \\
\hline \multicolumn{6}{|l|}{ Age } \\
\hline 20-34 & $5.6(1.2)^{c}$ & $3.9(0.9)^{c}$ & $54.9(7.9)^{\mathrm{c}}$ & $2.7(0.6)^{c}$ & $43.2(3.3)^{\mathrm{b}}$ \\
\hline $35-59$ & $18.5(1.0)$ & $11.0(0.7)$ & $58.0(2.4)$ & $6.4(0.5)$ & $60.0(2.7)$ \\
\hline$\geq 60$ & $27.3(1.8)$ & $21.5(1.6)$ & $79.0(1.5)$ & $9.6(0.4)$ & $44.1(2.8)$ \\
\hline \multicolumn{6}{|l|}{ Area of residence } \\
\hline Urban & $24.2(1.2)^{\mathrm{c}}$ & $16.0(0.9)^{\mathrm{c}}$ & $63.8(2.0)$ & $7.4(0.3)^{\mathrm{a}}$ & $46.8(1.9)^{\mathrm{c}}$ \\
\hline Rural & $13.8(0.9)$ & $9.0(0.7)$ & $61.3(2.8)$ & $5.6(0.6)$ & $66.6(4.3)$ \\
\hline \multicolumn{6}{|l|}{ Region } \\
\hline North & $15.7(1.1)^{\mathrm{c}}$ & $10.1(0.7)^{\mathfrak{c}}$ & $58.6(4.1)$ & $6.3(0.8)$ & $63.0(8.0)$ \\
\hline Central & $16.1(0.8)^{\mathrm{c}}$ & $11.2(0.7)^{\mathrm{c}}$ & $61.3(3.4)$ & $5.8(0.4)^{\mathrm{b}}$ & $56.3(3.4)$ \\
\hline Northeast & $14.2(2.3)^{\mathrm{c}}$ & $9.7(1.8)^{\mathrm{c}}$ & $64.4(2.9)$ & $6.8(1.5)$ & $69.0(2.3)^{\mathrm{c}}$ \\
\hline South & $18.3(0.8)^{\mathrm{c}}$ & $11.2(0.7)^{\mathrm{c}}$ & $60.7(4.0)$ & $5.5(0.5)^{\mathrm{b}}$ & $43.4(3.3)$ \\
\hline Bangkok & $30.1(1.1)$ & $19.8(1.2)$ & $59.8(2.9)$ & $8.2(0.6)$ & $48.8(3.5)$ \\
\hline \multicolumn{6}{|l|}{ Diabetes } \\
\hline Yes & $27.4(2.3)^{\mathrm{c}}$ & $21.3(1.8)^{\mathrm{c}}$ & $76.3(4.5)^{\mathrm{b}}$ & $8.1(1.4)$ & $39.7(2.6)^{c}$ \\
\hline No & $15.5(1.0)$ & $9.5(0.7)$ & $56.9(2.1)$ & $5.8(0.4)$ & $62.7(2.9)$ \\
\hline \multicolumn{6}{|l|}{ Hypertension } \\
\hline Yes & $25.5(1.5)^{c}$ & $17.8(1.3)^{\mathrm{c}}$ & $70.0(3.0)^{\mathrm{c}}$ & $9.3(0.7)^{\mathrm{c}}$ & $54.6(3.3)$ \\
\hline No & $13.0(0.9)$ & $7.5(0.6)$ & $53.5(2.0)$ & $4.5(0.4)$ & $61.8(2.7)$ \\
\hline \multicolumn{6}{|l|}{$\mathrm{CHD}$ risk stratification } \\
\hline $0-1 \mathrm{RF}$ & $14.8(1.1)^{\mathrm{c}}$ & $8.6(0.8)^{\mathrm{c}}$ & $51.7(2.3)^{\mathrm{c}}$ & $6.4(0.6)$ & $76.4(3.2)^{\mathrm{c}}$ \\
\hline $2+\mathrm{RF}$ and/or 10 -year risk $10-20 \%$ & $19.2(2.3)$ & $15.2(2.2)$ & $73.3(1.7)$ & $11.2(2.3)$ & $60.5(4.5)$ \\
\hline CHD risk equivalent (10-year risk >20\%) & $25.5(2.5)$ & $19.3(2.0)$ & $73.1(4.0)$ & $5.9(0.9)$ & $32.9(3.8)$ \\
\hline
\end{tabular}

Significant level: ${ }^{\mathrm{a}} P<0.05 ;{ }^{\mathrm{b}} \mathrm{P}<0.01 ;{ }^{\mathrm{c}} \mathrm{P}<0.001$.

$P$ values for comparison among age groups and among CHD risk stratification were $P$-for trend.

For comparison among regions: each region was compared with Bangkok. 
slightly lower than that of the Korean population reported in 2006 and $2012[9,24]$. The Korea health survey reported that the levels of TC, LDL-C, HDL-C, and triglycerides were $184.7,114,45.2$, and $135.2 \mathrm{mg} / \mathrm{dL}$, respectively, which were more favorable than what was found in the Thai population in the present study [9].

The findings of slightly higher levels of total cholesterol (TC) and LDL-C but lower level of triglycerides in women compared with men were consistent with a previous study [25] as well as other studies in Japan [26], Korea [27], and the U.S. [23]; however, the magnitudes of differences were smaller among the high-income countries. In the present study, the finding of higher TC and LDL-C in women is concordant with the higher prevalence of obesity and abdominal obesity in Thai women than in men [28]. Obesity and abdominal obesity affect lipid metabolism and contribute to dyslipidemia, whereas body weight reduction improves lipid abnormalities [3, 29].

The findings of high prevalence of dyslipidemia in Thai population might not be surprised as dietary pattern in the current Thai food has gradually changed from the past. The traditional Thai food normally constitutes low fat, high complex carbohydrate, and high fiber as compared with westernized food [30]. During the past several decades since 1960, the per capita consumption of cereals and tuber, particularly rice, has declined considerably compared with the early 1960 [31-33]. Consumption of animal products increased after 1975 with dramatic increases in 1985 [30, 33]. The changes in dietary pattern owing to the economic development and urbanization are likely to contribute to the current situation of dyslipidemia. Compared with the findings from a previous study in 2000 in five provinces [25], the levels of TC, LDL$\mathrm{C}$, non HDL-C, and triglycerides in the present study were higher; however, the pattern of differences across regions was relatively similar, as TC, LDL-C, and HDL-C remained higher in Bangkok and the central region, whereas people in the northeast had the lowest level of HDL-C and highest level of triglycerides. The different type of lipid abnormality is likely to be attributed to the different food pattern. The higher levels of TC, LDL-C, and HDL-C are likely to be related to urbanization, where people consume more meat and a fattier diet. People in the rural northeast usually consume more carbohydrates in the form of sticky rice. Men in rural areas also consume greater amounts of alcohol and carbohydrates but less protein and fat in their daily diet, which might contribute to the higher levels of triglycerides and lower cholesterol among the population in this region. Data from the Thai consumption survey reported that average daily consumptions of protein, fat, and carbohydrate were 72, 60, and 311 gram per person, respectively. Fat consumption was higher among urban household and carbohydrate consumption was higher in the rural areas [34]. People in the northeast had the lowest amount of fat consumption [34]. Compared to other regions, the proportions of energy intake from carbohydrate among northeast residents were the highest at $59.2 \%$ and from fat were the lowest at $23.3 \%$, whereas the corresponding percentages for people in Bangkok were at $54.4 \%$ and $31.4 \%$, respectively [32]. It is unlikely that the higher consumption of carbohydrate among the rural residents was due to the higher percentages of vegetarians in rural areas; however, this issue needs further investigation. With regard to the effect of high carbohydrate intake, a metaanalysis of 60 controlled studies showed that high dietary carbohydrate intake increased fasting triglyceride level and decreased HDL-C [35]. In addition, consumption of high glycemic index and glycemic load food has been reported to be associated with CHD [36]. However, research into the link of dietary pattern and other behavioral and environment factors with lipid profiles and health outcomes by region needs further investigation.

Another important finding in the present study is the markedly low percentage of awareness and treatment of LDL in the population. The overall control percentage among those treated was relatively moderate (58\%) and the percentages of attaining LDL-C targets were comparable to the findings from other studies in clinical settings $[15,16]$; however, this should be interpreted with caution, given the difference in sample characteristics, time of study, and tools to estimate CHD risk. In the U.S. study, the percentage of awareness of high LDL-C was $61.5 \%$, treatment among those aware was 70\%, and control among those treated was $63.6 \%$ [37]. The corresponding percentage for awareness in the present study was about 3.4 times lower, but percentages for treatment and control among those treated were only slightly lower. This finding might reflect that the effort to achieve a higher screening rate for detection of high serum cholesterol was more difficult than the effort to deliver treatment and control for those treated for hypercholesterolemia, which is consistent with a previous study [12].

Although Thailand has a good infrastructure of district health hospitals distributed throughout the country, the shortage of manpower and laboratory facilities to screen and monitor serum cholesterol and type of cholesterol remains a problem, particularly in rural areas. This is shown by the even lower percentages in rural areas compared with urban areas and lower percentages in the peripheral regions as compared with Bangkok. Since the previous decade, the Ministry of Public Health has spent a great deal of effort in an attempt to increase the coverage in screening for diabetes and hypertension, due to the higher burden of hypertension and diabetes compared to hypercholesterolemia in the Thai population [38]; however, for dyslipidemia, more resources are needed for investment in rural health care services. A study reported that Thailand had invested less efficiently compared with Mexico in terms of provision of medication [39]. Further intervention for efficient allocation of technical resources and workforce is required to scale up the facilities for screening programs and therapeutic lifestyle changes. It should be noted that when comparing to those without diabetes, hypertension, or moderate/high CHD risk, the percentages of awareness and treatment among those with the conditions were higher. This might be due to the fact that they were patients in the health service system, so the conditions were more likely to be detected and treated with medication. However, the findings of worse control among 
these groups are consistent with other studies [15-17, 37]. Since guidelines in the management of dyslipidemia are available $[4,5]$, further efforts are needed to improve LDL$\mathrm{C}$ control in those with diagnosed high LDL-C, particularly for those at high risk of CHD.

Some limitations in the present study need to be mentioned. Measurement of lipids for each participant was done at a single point in time, and data on type of medication is not known. The estimation of CHD risk was based on an international WHO prediction score. The estimation might misclassify the risk category; however, we used a Thai coronary heart risk score to estimate the risk and the findings did not change substantially [40]. Treatment information was based on self-reports and did not include lifestyle modification or other herbal medication. Despite the limitations, the present study is the first national representative population-based study with a large sample size and provides more detailed information on dyslipidemia in Thai adults. The use of the WHO prediction chart for estimation of $\mathrm{CHD}$ risk should provide more useful information to stratify individuals' risk. In conclusion, dyslipidemia is a common condition with various forms in Thai adults. Effective intervention to promote healthy dietary intake and increased physical activity should be intensified at the population level. Appropriate screening, treatment, and therapeutic lifestyle change programs for high-risk groups must be scaled up.

\section{Conflict of Interests}

The authors declare that there is no conflict of interests regarding the publication of this paper.

\section{Authors' Contribution}

Wichai Aekplakorn designed the study, performed data analysis, and drafted the paper. Pattapong Kessomboon, Virasakdi Chongsuvivatwong, Panwadee Putwatana, Surasak Taneepanichskul, and Suwat Chariyalertsak participated in the study design and carried out field data collection. Piyamitr Sritara and Somkiat Sangwatanaroj participated in the study design and revised the paper. All authors read and approved the final paper.

\section{Acknowledgments}

NHES IV was conducted by the National Health Examination Survey Office, Health Systems Research Institute, Thailand. The NHES IV study group included the National Health Examination Survey Office: Wichai Aekplakorn, Rungkarn Inthawong, Jiraluck Nonthaluck, Supornsak Tipsukum, Yawarat Porrapakkham; Northern region: Suwat Chariyalertsak, Kanittha Thaikla (Chiang Mai University), Wongsa Laohasiriwong, Wanlop Jaidee, Sutthinan Srathonghon, Ratana Phanphanit, Jiraporn Suwanteerangkul, and Kriangkai Srithanaviboonchai; Northeastern region: Pattapong Kessomboon, Somdej Pinitsoontorn, Piyathida Kuhirunyaratn, Sauwanan Bumrerraj, Amornrat Rattanasiri, Suchada Paileeklee, Bangornsri Jindawong, Napaporn Krusun, and
Weerapong Seeupalat (Khon Kaen University); Southern region: Virasakdi Chongsuvivatwong, Rassamee Sangthong, and Mafausis Dueravee (Prince of Songkla University); Central region: Surasak Taneepanichskul, Somrat Lertmaharit, Vilai Chinveschakitvanich, Onuma Zongram, Nuchanad Hounnaklang, and Sukarin Wimuktayon (Chulalongkorn University); Bangkok region: Panwadee Putwatana, Chalermsri Nuntawan, and Karn Chaladthanyagid (Mahidol University). The Thai National Health Examination Survey IV was supported by the Health Systems Research Institute; Bureau of Policy and Strategy, Ministry of Public Health; Thai Health Promotion Foundation; and the National Health Security Office, Thailand. The authors thank Professor Amnuay Thithapandha, Faculty of Medicine, Mahidol University, for his help in editing the paper.

\section{References}

[1] National Cholesterol Education Program (NCEP) Expert Panel on Detection and Evaluation, and Treatment of High Blood Cholesterol in Adults (Adult Treatment Panel III), "Third report of the national cholesterol education program (NCEP) expert panel on detection, evaluation, and treatment of high blood cholesterol in adults (adult treatment panel III) final report," Circulation, vol. 106, no. 25, pp. 3143-3421, 2002.

[2] S. M. Grundy, J. I. Cleeman, C. N. B. Merz et al., "Implications of recent clinical trials for the national cholesterol education program adult treatment panel III guidelines," Circulation, vol. 110, no. 2, pp. 227-239, 2004.

[3] Z. Reiner, A. L. Catapano, G. de Backer et al., "ESC/EAS guidelines for the management of dyslipidaemias: the task force for the management of dyslipidaemias of the European society of cardiology (ESC) and the European atherosclerosis society (EAS)," European Heart Journal, vol. 32, no. 14, pp. 1769-1818, 2011.

[4] N. J. Stone, J. Robinson, A. H. Lichtenstein et al., "ACC/AHA guideline on the treatment of blood cholesterol to reduce atherosclerotic cardiovascular risk in adults: a report of the American college of cardiology/American heart association task force on practice guidelines," Journal of the American College of Cardiology, 2013.

[5] T. J. Anderson, J. Gregoire, R. A. Hegele et al., "2012 update of the Canadian cardiovascular society guidelines for the diagnosis and treatment of dyslipidemia for the prevention of cardiovascular disease in the adult," Canadian Journal of Cardiology, vol. 29, no. 2, pp. 151-167, 2013.

[6] M. J. Jacobs, T. Kleisli, J. R. Pio et al., "Prevalence and control of dyslipidemia among persons with diabetes in the United States," Diabetes Research and Clinical Practice, vol. 70, no. 3, pp. 263269, 2005.

[7] H. Ghandehari, S. Kamal-Bahl, and N. D. Wong, "Prevalence and extent of dyslipidemia and recommended lipid levels in US adults with and without cardiovascular comorbidities: the national health and nutrition examination survey 2003-2004," The American Heart Journal, vol. 156, no. 1, pp. 112-119, 2008.

[8] S. G. Goodman, A. Langer, N. R. Bastien et al., "Prevalence of dyslipidemia in statin-treated patients in Canada: results of the DYSlipidemia International Study (DYSIS)," Canadian Journal of Cardiology, vol. 26, no. 9, pp. e330-e335, 2010. 
[9] S. J. Choi, S. H. Park, K. S. Lee, and H. Y. Park, "The prevalence, awareness and treatment of high low density lipoproteincholesterol in Korean adults without coronary heart diseasesthe third Korea national health and nutrition examination survey, 2005," Korean Circulation Journal, vol. 42, no. 2, pp. 8694, 2012.

[10] E. S. Ford, C. Li, W. S. Pearson, G. Zhao, and A. H. Mokdad, "Trends in hypercholesterolemia, treatment and control among United States adults," International Journal of Cardiology, vol. 140, no. 2, pp. 226-235, 2010.

[11] A. Kuznik and J. Mardekian, "Trends in utilization of lipid- and blood pressure-lowering agents and goal attainment among the U.S. diabetic population, 1999-2008," Cardiovascular Diabetology, vol. 10, article 31, 2011.

[12] G. A. Roth, S. D. Fihn, A. H. Mokdad, W. Aekplakorn, T. Hasegawa, and S. S. Lim, "High total serum cholesterol, medication coverage and therapeutic control: an analysis of national health examination survey data from eight countries," Bulletin of the World Health Organization, vol. 89, no. 2, pp. 92101, 2011.

[13] M. J. Chapman, H. N. Ginsberg, P. Amarenco et al., "Triglyceride-rich lipoproteins and high-density lipoprotein cholesterol in patients at high risk of cardiovascular disease: evidence and guidance for management," European Heart Journal, vol. 32, no. 11, pp. 1345-1361, 2011.

[14] M. Miller, N. J. Stone, C. Ballantyne et al., "Triglycerides and cardiovascular disease: a scientific statement from the American heart association," Circulation, vol. 123, no. 20, pp. 2292-2333, 2011.

[15] W. Nitiyanant, P. Sritara, C. Deerochanawong, P. Ngarmukos, and B. Koanantakul, "Lipid treatment assessment project II in Thailand (LTAP-II Thailand)," Journal of the Medical Association of Thailand, vol. 91, no. 6, pp. 836-845, 2008.

[16] W. Khovidhunkit, S. Silaruks, V. Chaithiraphan et al., "Prevalence of dyslipidemia and goal attainment after initiating lipidmodifying therapy: a Thai multicenter study," Angiology, vol. 63, no. 7, pp. 528-534, 2012.

[17] H. S. Kim, Y. Wu, S. J. Lin et al., "Current status of cholesterol goal attainment after statin therapy among patients with hypercholesterolemia in Asian countries and region: the return on expenditure achieved for lipid therapy in Asia (REALITY-Asia) study," Current Medical Research and Opinion, vol. 24, no. 7, pp. 1951-1963, 2008.

[18] W. Aekplakorn, R. Sangthong, P. Kessomboon et al., "Changes in prevalence, awareness, treatment and control of hypertension in Thai population, 2004-2009: Thai national health examination survey III-IV," Journal of Hypertension, vol. 30, no. 9, pp. 1734-1742, 2012.

[19] W. T. Friedewald, R. I. Levy, and D. S. Fredrickson, "Estimation of the concentration of low-density lipoprotein cholesterol in plasma, without use of the preparative ultracentrifuge," Clinical Chemistry, vol. 18, no. 6, pp. 499-502, 1972.

[20] G. L. Myers, G. R. Cooper, C. L. Winn, and S. J. Smith, "The centers for disease control-national heart, lung and blood institute lipid standardization program. An approach to accurate and precise lipid measurements," Clinics in Laboratory Medicine, vol. 9, no. 1, pp. 105-135, 1989.

[21] Prevention of Cardiovascular Disease, Pocket Guidelines for Assessment and Management of Cardiovascular Risk, WHO/ISH Cardiovascular Risk Prediction Charts for 14 WHO Epidemiological Sub-Regions, World Health Organization, Genava, Switzerland, 2007.
[22] M. D. Carroll, B. K. Kit, D. A. Lacher, S. T. Shero, and M. E. Mussolino, "Trends in lipids and lipoproteins in US adults, 1988-2010," The Journal of the American Medical Association, vol. 308, no. 15, pp. 1545-1554, 2012.

[23] M. D. Carroll, B. K. Kit, D. A. Lacher, S. T. Shero, and M. E. Mussolino, "Trends in lipids and lipoproteins in US adults, 1988-2010," The Journal of the American Medical Association, vol. 308, no. 15, pp. 1545-1554, 2012.

[24] S. M. Kim, J. H. Han, and H. S. Park, "Prevalence of low HDL-cholesterol levels and associated factors among Koreans," Circulation Journal, vol. 70, no. 7, pp. 820-826, 2006.

[25] V. Chongsuvivatwong, T. Yipintsoi, P. Suriyawongpaisal et al., "Comparison of cardiovascular risk factors in five regions of Thailand: InterASIA data," Journal of the Medical Association of Thailand, vol. 93, no. 1, pp. 17-26, 2010.

[26] H. Arai, A. Yamamoto, Y. Matsuzawa et al., "Serum lipid survey and its recent trend in the general Japanese population in 2000," Journal of Atherosclerosis and Thrombosis, vol. 12, no. 2, pp. 98106, 2005.

[27] G. E. Nam, K. H. Cho, Y. G. Park et al., "Socioeconomic status and dyslipidemia in Korean adults: the 2008-2010 Korea national health and nutrition examination survey," Preventive Medicine, vol. 57, no. 4, pp. 304-309, 2013.

[28] W. Aekplakorn, P. Kessomboon, R. Sangthong et al., "Urban and rural variation in clustering of metabolic syndrome components in the Thai population: results from the fourth national health examination survey 2009," BMC Public Health, vol. 11, article 854, 2011.

[29] A. M. Dattilo and P. M. Kris-Etherton, "Effects of weight reduction on blood lipids and lipoproteins: a meta-analysis," The American Journal of Clinical Nutrition, vol. 56, no. 2, pp. 320-328, 1992.

[30] V. Kosulwat, "The nutrition and health transition in Thailand," Public Health Nutrition, vol. 5, no. 1, pp. 183-189, 2002.

[31] Food Security and Nutrition Status in Thailand, 2005-2011, National Statistical Office and Office of Agricultural Economics of the Kingdom of Thailand, Bangkok, Thailand, 2012.

[32] W. Aekplakorn, Food Consumption Survey of Thai Population, the Fourth National Health Examination Survey, Thailand, 2009, National Health Examination Survey Office, Health System Research Institute, Nonthaburi, Thailand, 2011.

[33] The Fourth National Nutirtional Survey of Thailand 1995, Department of Health, Ministry of Public Health, Bangkok, Thailand, 1997

[34] Food Insecurity Assessment at National and Subnational Levels in Thailand, 2011, National Statistical Office and Office of Agriculture Economic of the Kingdom of Thailand, Bangkok, Thailand, 2012

[35] R. P. Mensink, P. L. Zock, A. D. M. Kester, and M. B. Katan, "Effects of dietary fatty acids and carbohydrates on the ratio of serum total to HDL cholesterol and on serum lipids and apolipoproteins: a meta-analysis of 60 controlled trials," The American Journal of Clinical Nutrition, vol. 77, no. 5, pp. 1146$1155,2003$.

[36] A. Mirrahimi, R. J. de Souza, L. Chiavaroli et al., "Associations of glycemic index and load with coronary heart disease events: a systematic review and meta-analysis of prospective cohorts," Journal of the American Heart Association, vol. 1, no. 5, Article ID e000752, 2012.

[37] P. Muntner, E. B. Levitan, T. M. Brown et al., "Trends in the prevalence, awareness, treatment and control of high low 
density lipoprotein-cholesterol among United States adults from 1999-2000 through 2009-2010," The American Journal of Cardiology, vol. 112, no. 5, pp. 664-670, 2013.

[38] K. Bundhamcharoen, P. Odton, S. Phulkerd, and V. Tangcharoensathien, "Burden of disease in Thailand: changes in health gap between 1999 and 2004," BMC Public Health, vol. 11, article 53, 2011.

[39] G. King, E. Gakidou, K. Imai et al., "Public policy for the poor? A randomised assessment of the Mexican universal health insurance programme," The Lancet, vol. 373, no. 9673, pp. 14471454, 2009.

[40] T. Yingchoncharoen, T. Limpijankit, S. Jongjirasiri, J. Laothamatas, S. Yamwong, and P. Sritara, "Arterial stiffness contributes to coronary artery disease risk prediction beyond the traditional risk score (RAMA-EGAT score)," Heart Asia, vol. 4, no. 1, pp. 77-82, 2012. 

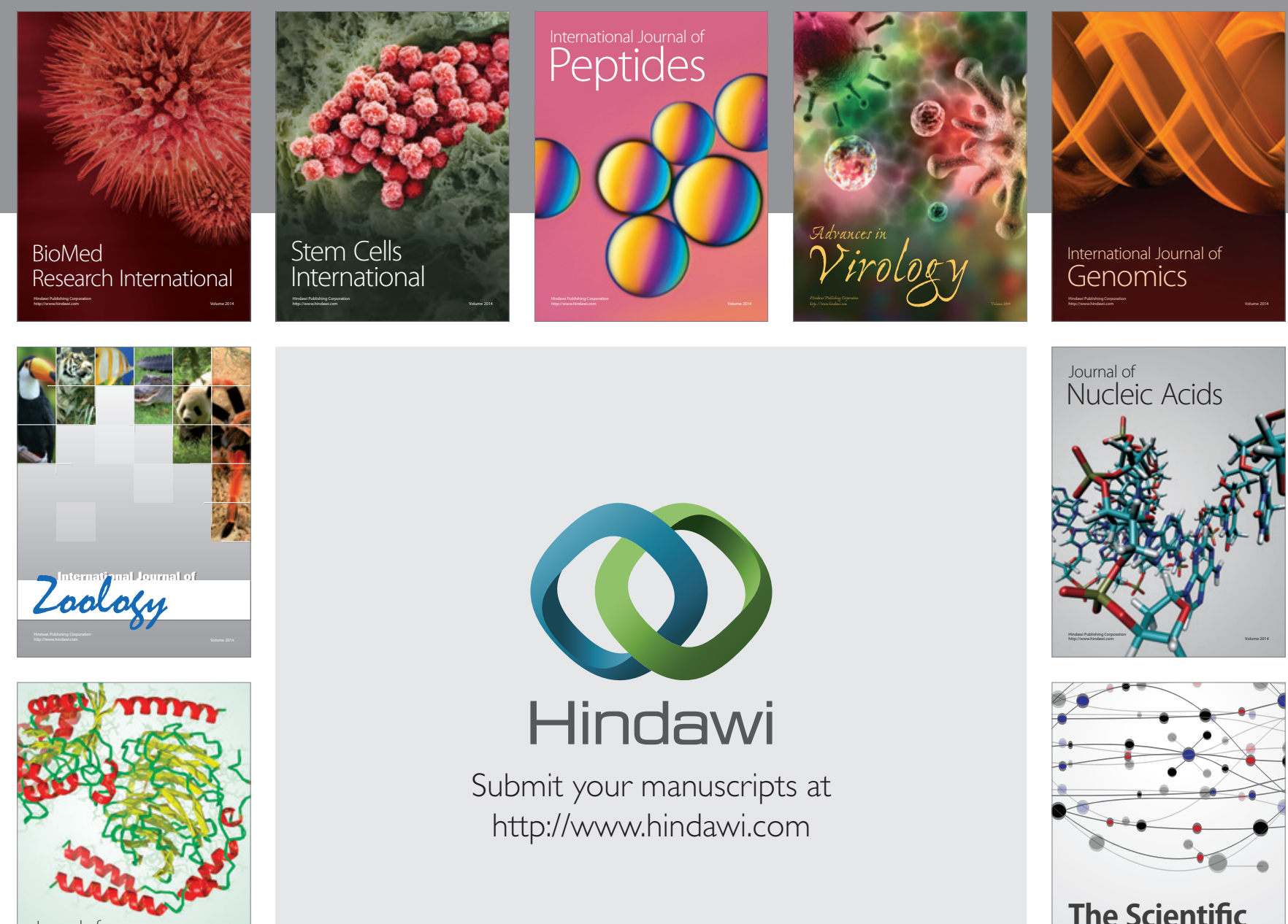

Submit your manuscripts at

http://www.hindawi.com

Journal of
Signal Transduction
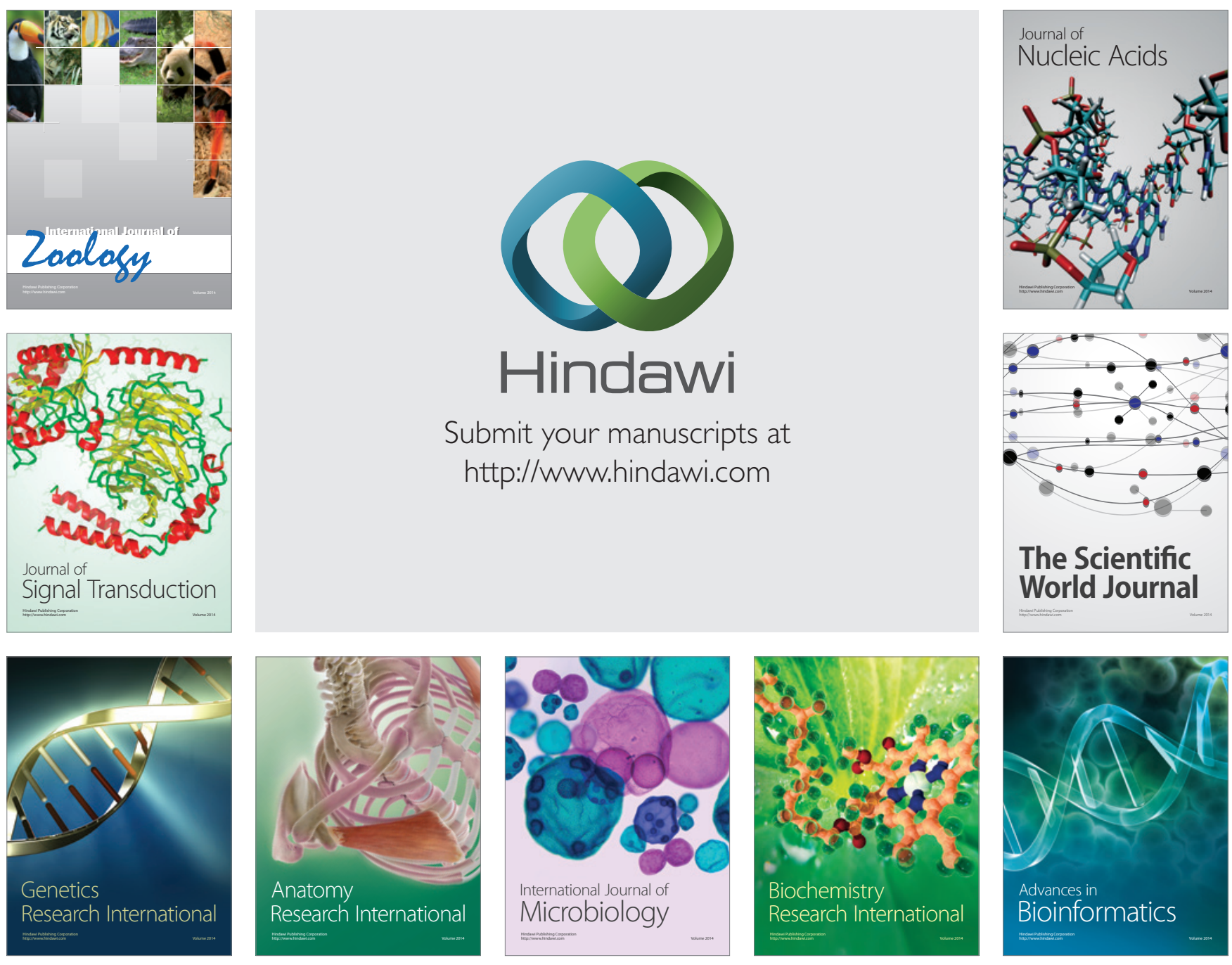

The Scientific World Journal
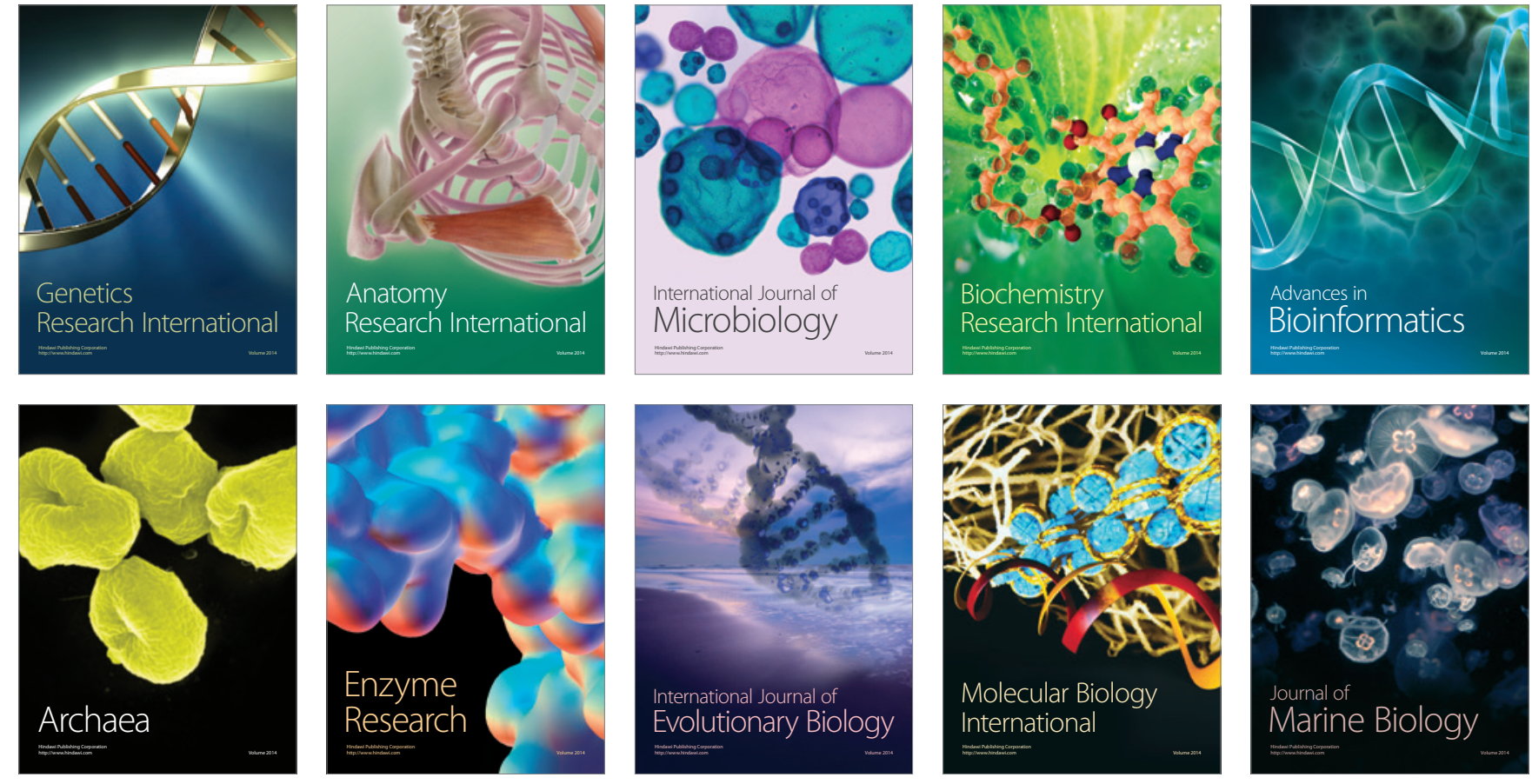